\title{
A simple fluorimetric method for the estimation of free 11-hydroxycorticoids in human plasma
}

\author{
D. MATTINGLY \\ From the Department of Medicine, Postgraduate Medical School, London
}

SYNOPSIS A simple fluorimetric method is described for measuring free 11-hydroxycorticoids in human plasma. Only $2 \mathrm{ml}$. of plasma is required for each estimation and the fluorescence is read in a standard direct reading fluorimeter. Six estimations can be completed in one and a half hours. It thus compares favourably with the methods in current use for estimating urinary steroids, and has the added advantage of not being dependent on the accurate collection of 24-hour urine samples.

The concentration of free plasma cortisol (hydrocortisone) in peripheral blood is a useful measure of adrenal activity, provided that the normal diurnal rhythm of the plasma steroids is taken into account (Bayliss, 1955). However, little use has been made of plasma cortisol concentrations in clinical practice because of the difficulties involved in measuring the small amounts of steroid present.

Most of the methods previously described are either based on the Porter-Silber reaction for 17hydroxycorticoids (Nelson and Samuels, 1952), or on the measurement of the fluorescence of the individual steroids after their separation by chromatography (Sweat, 1954; Lewis, 1957; Bondy, Abelson, Scheuer, Tsen, and Upton, 1957; Braunsberg and James, 1960). All these methods require at least $5 \mathrm{ml}$. of plasma for a single estimation and are too laborious for routine clinical use.

In the past four years a number of methods have been developed for measuring free corticosterone in rat plasma (Silber, Busch, and Oslapas, 1958; Guillemin, Clayton, Smith, and Lipscomb, 1958; Zenker and Bernstein, 1958; van der Vies, Bakker, and De Wied, 1960). These methods depend on the specific fluorescence of 11-hydroxycorticoids in concentrated sulphuric acid and can be applied to crude plasma extracts. In man, in contrast to the rat, the main free 11-hydroxycorticoid in plasma is cortisol, although corticosterone is also present in much smaller amounts (Bush and Sandberg, 1953).

De Moor, Steeno, Raskin, and Hendrikx (1960) have used this fluorescent technique to measure the free plasma 11-hydroxycorticoids in small samples of human plasma. The method described here is based on their method, but a number of modifications Received for publication 13 December 1961. were necessary before satisfactory results were obtained. Since both cortisol and corticosterone are secreted by the adrenal cortex the fact that both are measured by this method does not detract from its usefulness as a measure of adrenal cortical activity.

An attempt to distinguish between the two steroids, using sulphuric acid-induced fluorescence, has been made quite recently by Stewart, Albert-Recht, and Osman (1961). For practical purposes this distinction appears to be unnecessary and their method is rather more laborious than the one described in this paper, making it less suitable for routine clinical use.

\section{METHODS}

REAGENTS The following are required:-

1 Methylene chloride (B.D.H.) Stand over concentrated sulphuric acid for several days with occasional shaking. One litre volumes are then further washed by shaking with (a) $100 \mathrm{ml}$. of concentrated sulphuric acid, (b) $100 \mathrm{ml}$. of $1 \mathrm{~N} \mathrm{NaOH}$, and (c) two washes of $200 \mathrm{ml}$. distilled water. Dry over anhydrous sodium sulphate for 24 hours. Distil, and collect the fraction which comes over between 39 and $40^{\circ} \mathrm{C}$. in a Pyrex flask and keep in the dark. This procedure is essential to keep the reagent blank as low as possible.

\section{Concentrated sulphuric acid A.R. \\ 3 Sodium hydroxide pellets A.R. \\ 4 Anhydrous sodium sulphate A.R. \\ 5 Ethyl alcohol R.R.}

6 Fluorescence reagent Add 7 volumes of concentrated sulphuric acid to 3 volumes of ethyl alcohol in a flask which is cooled under a cold water tap. The solution should remain colourless. If a brown colour develops, purify the ethyl alcohol (Peterson, Wyngaarden, Guerra, Brodie, and Bunim, 1955). This reagent is stable at room temperature. 
7 Cortisol standards Dissolve $50 \mathrm{mg}$. cortisol (alcohol) in $50 \mathrm{ml}$. of purified ethyl alcohol. Dilute $1 \mathrm{ml}$. of this solution to $100 \mathrm{ml}$. with distilled water $(10 \mu \mathrm{g}$. per $\mathrm{ml}$.). These solutions remain stable for months at $\pm 4^{\circ} \mathrm{C}$. Standard solutions containing $1 \mu \mathrm{g}$. per $\mathrm{ml}$. only remain stable for about a month and are prepared when required by further dilution of the $10 \mu \mathrm{g}$. per $\mathrm{ml}$. standard.

APPARATUS Clean all glassware with chromic acid, followed by thorough washing with tap water and finally distilled water. Use a rubber propipette ${ }^{1}$ to pipette methylene chloride and acid. Plug all pipettes with cotton wool when using a propipette to prevent rubber particles contaminating solutions. Failure to do this will result in falsely high fluorimetric readings.

DIRECT READING FLUORIMETER ${ }^{2}$ This is a sensitive and stable instrument designed to make fluorimetric analysis as simple and accurate as possible. Samples, each of $5 \mathrm{ml}$., are used and eight matched glass cells are required in order to read six plasma extracts, one standard and a blank simultaneously. The exciting light is provided by a mercury lamp and the primary filter used (Chance OB 10 blue) has a peak transmission at about $430 \mathrm{~m} \mu$. Secondary filters (Chance $0 \mathrm{Gr} 1$ and $\mathrm{OY} 3$ ) give a peak transmission around $540 \mathrm{~m} \mu$, whilst excluding light below $510 \mathrm{~m} \mu$. Excitation at 470 to $480 \mathrm{~m} \mu$ would be preferable (Sweat, 1954) but this is not possible when a mercury lamp is used as the exciting source.

COLLECTION OF BLOOD Blood is obtained by venipuncture, using heparin as an anticoagulant. Provided the blood is refrigerated immediately it is not necessary to separate the plasma for at least 12 hours (Wu and Mason, 1958; De Moor et al., 1960). If necessary, plasma can be stored up to 72 hours at $\pm 4^{\circ} \mathrm{C}$.

EXTRACTION OF FREE STEROIDS FROM PLASMA Two alternative methods of extraction can be used.

Flask extraction Pipette $2.0 \mathrm{ml}$. of plasma into a $250 \mathrm{ml}$. conical flask. Add $15.0 \mathrm{ml}$. of methylene chloride. Shake the flask gently by hand or in a slow mechanical shaker for 10 minutes. No emulsion should form. Decant off 12 to $13 \mathrm{ml}$. of the methylene chloride extract into a $20 \mathrm{ml}$. glass-stoppered extraction tube.

Tube extraction A simple extraction machine enables a large number of plasmas to be extracted simultaneously. This consists of a metal disc which is rotated in the vertical plane at 33 r.p.m. by an electric motor. Around the circumference of the disc are 18 clips so arranged that they will hold a $20 \mathrm{ml}$. extraction tube with its long axis in the horizontal plane. Pipette $2.0 \mathrm{ml}$. of plasma on to the top of $15.0 \mathrm{ml}$. of methylene chloride in $20 \mathrm{ml}$. glassstoppered extraction tubes. Make sure that tubes are firmly stoppered and place in clips. Rotate for $\mathbf{2 0}$ minutes. Suck off supernatant plasma.

A reagent blank $(2.0 \mathrm{ml}$. distilled water $)$ and cortisol standard $(2.0 \mu \mathrm{g}$.) are run through the procedure with each batch of six plasmas. Extracts can be stored for at least 24 hours at $\pm 4^{\circ} \mathrm{C}$. if necessary.

${ }^{1}$ Hoslab Ltd.

:Model 27 A, Electronics Instruments Limited.
FLUORIMETRY Fluorimetry should be done in batches of not more than six plasma extracts, a blank, and a cortisol standard. Careful timing is necessary to keep the interference of non-specific fluorescence at as low and uniform a level as possible. At zero time add $10.0 \mathrm{ml}$. of the blank extract to $5.0 \mathrm{ml}$. of the fluorescence reagent in a $20 \mathrm{ml}$. glass-stoppered extraction tube, using a pipette. Shake vigorously for 20 seconds. Repeat this procedure for the standard and for each of the plasma extracts at oneminute intervals. Suck off the supernatant methylene chloride from each tube in turn, starting with the blank. Transfer the acid extracts between aspiration to a separate glass cell preparatory to reading.

Measure secondary emitted light 13 minutes after mixing the extracts with the fluorescence reagent. Set the blank to read zero on sensitivity range 1 of the instrument. One minute later set the cortisol standard to read 100.0 on sensitivity range 2 . Then read the fluorescence of the unknowns on sensitivity range 2 at one-minute intervals, in the order of mixing. Since a $2 \cdot 0 \mu \mathrm{g}$. cortisol standard is used the reading on sensitivity range 2 is the plasma 11-hydroxycorticoid concentration in $\mu \mathrm{g} . / 100 \mathrm{ml}$. expressed as cortisol. As the cells may not be perfectly matched these readings may be subject to a small cell correction which can be determined by comparing the fluorescence of the fluorescence reagent alone in all eight cells.

\section{RESULTS}

There is a rise in the fluorescence of the plasma extracts with time after mixing, relative to the fluorescence of the cortisol standard. Timing is necessary to ensure that the level of this non-specific fluorescence remains relatively constant from estimation to estimation. De Moor et al. (1960) measured the fluorescence five minutes after mixing, but only two plasma extracts can be measured simultaneously in this time working single-handed.

In order to increase the number of estimations which can be done simultaneously it was necessary to determine the magnitude of this rise. Experiments were done in which the fluorescence of a large number of plasma extracts was measured at varying times after mixing, relative to the cortisol standard read at the same time. The mean increases in plasma fluorescence produced by delays of varying times above 10 minutes are shown in Table $I$.

It will be seen that between 10 and 20 minutes after mixing the mean increase in plasma fluorescence was only $0.5 \mu \mathrm{g}$. per $100 \mathrm{ml}$. when the plasma 11 hydroxycorticoid concentration was less than $30 \mu \mathrm{g}$. per $100 \mathrm{ml}$. and was rarely greater than $1.0 \mu \mathrm{g}$. per $100 \mathrm{ml}$. (mean +2 S.D.). Thus at normal plasma levels an error of not more than $13 \%$ is introduced by a delay of 10 minutes in measuring the fluorescence. Thirteen minutes after mixing was chosen to enable six plasma extracts to be measured simultaneously. 


\section{TABLE I}

INCREASE IN PLASMA FLUORESCENCE ABOVE THE READING AT 10 MINUTES AT VARYING TIMES AFTER MIXING ${ }^{1}$

\begin{tabular}{clc}
$\begin{array}{l}\text { Time after Mixing } \\
\text { (minutes) }\end{array}$ & \multicolumn{2}{c}{ Plasma Reading at 10 Minutes $(\mathrm{mg} . / 100 \mathrm{ml}$.) } \\
\cline { 2 - 3 } & 0 to 29.9 & 30 to 100 \\
\hline 20 & $0.5 \pm 0.7(65)$ & $1.1 \pm 1.0(17)$ \\
30 & $0.8 \pm 0.8(107)$ & $1.5 \pm 1.6(58)$ \\
60 & $1.5 \pm 1.3(30)$ & $4.0 \pm 2.4(10)$
\end{tabular}

The mean and standard deviation are given for each group. The figures in brackets are the number of observations in each group.

However, it is probable that equally consistent results could be obtained at any time between 10 and 20 minutes after mixing, during which period the fluorescence of the cortisol standard remains fairly constant.

CORRELATION BETWEEN TWO EXTRACTION PROCEDURES Forty plasmas, of which the 11-hydroxycorticoid concentrations ranged from 0.5 to $130 \mu \mathrm{g}$. per $100 \mathrm{ml}$., were extracted by both the procedures described above. The correlation coefficient ( $r$ ) was $1.0(P<0.001)$. The recovery of ${ }^{4-14} \mathrm{C}$ cortisol from the same plasma was identical $(95 \%)$.

PRECISION The precision of the method has been assessed by the criteria suggested by Brown, Bulbrook, and Greenwood (1957). Standard deviations for different plasma concentrations were calculated from the differences between duplicate estimations (Snedecor, 1952). These were determined for duplicate estimations measured simultaneously and for duplicate estimations on different days (replicate estimations). Plasma samples, each of $2.0 \mathrm{ml}$., were used as smaller samples did not give satisfactory duplicate readings when the plasma 11-hydroxycorticoid concentration was less than $30 \mu \mathrm{g}$. per $100 \mathrm{ml}$. The results are recorded in Table II.

\section{TABLE II}

STANDARD DEVIATION OF DUPLICATE DETERMINATIONS

\begin{tabular}{|c|c|c|c|c|}
\hline & \multicolumn{4}{|c|}{ 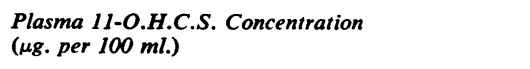 } \\
\hline & 0 to 9.9 & 10 to 19.9 & 20 to 39.9 & 40 to 130 \\
\hline $\begin{array}{l}\text { Simultaneous } \\
\text { estimations }\end{array}$ & $0.9(31)$ & $1.0(47)$ & $1 \cdot 0(34)$ & $1.6(28)$ \\
\hline $\begin{array}{l}\text { Replicate } \\
\text { estimations }\end{array}$ & $1.4(37)$ & $1.6(34)$ & $1.9(28)$ & $2 \cdot 1(28)$ \\
\hline
\end{tabular}

Figures in brackets are the number of observations in each group.

The smallest single result which can be distinguished from zero with some certainty is $2.8 \mu \mathrm{g}$. per $100 \mathrm{ml}$. $(t=2.0 ; P<0.05)$. The fiducial range of duplicate estimations, when the plasma 11-hydroxycorticoid concentration is less than $10 \mu \mathrm{g}$. per $100 \mathrm{ml}$., is the mean $\pm 2.0 \mu \mathrm{g}$. per $100 \mathrm{ml}$. $(\mathrm{t}=2.0 ; \mathrm{P}<0.05)$.

ACCURACY When cortisol and corticosterone standards ranging from 0.1 to $2.0 \mu \mathrm{g}$. were taken through the procedure a linear relationship was found between the fluorescence intensity and the concentration of steroid. Cortisol recovery was determined on 12 occasions by measurements on duplicate samples of plasma. To one of each pair was added 0.5 or $1.0 \mu \mathrm{g}$. of the steroid. The range was 93 to $104 \%$, mean $98.2 \%$. The recovery of ${ }^{4}-{ }^{14} \mathrm{C}$ cortisol from plasma was similar $(95.4$ and $98.1 \%$ ) and did not differ significantly from the recovery from distilled water $(98 \cdot 3 \%)$.

SPECIFICITY The specificity of this fluorescent technique has been fully investigated by others (Sweat, 1954; Silber et al., 1958; Zenker and Bernstein, 1958; De Moor et al., 1960). A small number of steroids were taken through the procedure and their relative fluorescence to cortisol is shown in Table III. The synthetic steroids produced very

\section{TABLE III}

FLUORESCENCE OF STEROIDS AS A PERCENTAGE OF FLUORESCENCE OF CORTISOL

\begin{tabular}{lc} 
Steroid $(2 \mu g)$. & $\%$ \\
\hline Cortisol & $100 \cdot 0$ \\
Corticosterone & $252 \cdot 0$ \\
Cortisone & 0 \\
Tetrahydro-cortisol & $5 \cdot 0$ \\
11-Deoxycortisol (s) & $2 \cdot 8$ \\
Prednisone & $1 \cdot 4$ \\
Prednisolone & 0 \\
Methylprednisolone & $2 \cdot 6$ \\
Fluorocortisone & $2 \cdot 9$ \\
Triamcinolone & $1 \cdot 2$ \\
Triamcinolone acetonide & $2 \cdot 1$ \\
Dexamethasone & 0 \\
Paramethasone acetate & 0 \\
Betamethasone & 0 \\
Betamethasone disodium phosphate & 0 \\
Oestriol & $6 \cdot 0$ \\
Oestrone & $23 \cdot 2$
\end{tabular}

little fluorescence, but oestradiol produced a considerable amount of fluorescence which was not significantly reduced by washing the extract with $0.1 \mathrm{~N} \mathrm{NaOH}$. However, oestradiol does not appear to be present in significant amounts in plasma even during pregnancy (Roy and Brown, 1960). Cortisone and the synthetic steroids, $2 \mu \mathrm{g}$., was added to plasma to see if there was any quenching of the plasma fluorescence, but none was found. Some quenching was found in icteric plasma but this could be removed by washing the extract with $0.1 \mathrm{~N} \mathrm{NaOH}$. 
No interference from drugs administered to patients has been found with the exception of M.E.R. 29 (Triparanol) which was being given to a patient with idiopathic hypercholesterolaemia. The drug itself did not fluoresce and other patients with hypercholesterolaemia had normal plasma 11hydroxycorticoid levels. Since this drug is said to interfere with cholesterol metabolism it is possible that the excessive fluorescence found in this patient's plasma was due to the presence of an abnormal steroid.

Finally, the results of 87 duplicate estimations were compared with single estimations of the 17hydroxycorticoid concentrations estimated by the method of Peterson et al. (1957). The correlation coefficient (r) was 0.97 over a range of 0 to $90 \mu \mathrm{g}$. per $100 \mathrm{ml}$. $(\mathrm{P}<0.001)$. This is a very good correlation considering that the two methods measure not only cortisol but also smaller amounts of other steroids present in the plasma.

NORMAL VALUeS Plasma 11-hydroxycorticoid concentrations were measured in 52 hospital patients whose ages ranged from 15 to 76 (mean 43). Patients with endocrine, liver, and renal disease were excluded. None of these patients was acutely ill at the time or being subjected to stressful procedures. Blood was taken between 9 and 10 a.m. to exclude variations due to the normal diurnal rhythm of the plasma steroids, which may be large. Levels ranged from 6.5 to $26.3 \mu \mathrm{g}$. per $100 \mathrm{ml}$. (arithmetic mean 14-2). There was no significant sex or age difference, the mean for 25 men being 13.7 and the mean for 27 women being $14.7 \mu \mathrm{g}$. per $100 \mathrm{ml}$.

NON-SPECIFIC PLASMA FLUORESCENCE The contribution of other substances in the plasma to the total fluorescence can only be determined in plasma from patients secreting negligible amounts of endogenous corticosteroids. Two groups of patients were studied. The first consisted of 13 patients whose pituitaries had been destroyed by the implantation of ${ }^{90} \mathrm{Yt}$ and who were judged to be cortisone-dependent by other criteria (Fraser and Joplin, 1960). All these patients were showing signs of acute adrenal insufficiency at the time blood was taken, following withdrawal of maintenance steroid therapy. The mean plasma fluorescence was $2.5 \mu \mathrm{g}$. per $100 \mathrm{ml}$., the range being 0 to $4 \cdot 2 \mu \mathrm{g}$. per $100 \mathrm{ml}$. The second group of patients was receiving synthetic corticosteroids by mouth in doses which were thought to be sufficient to suppress endogenous corticosteroid secretion completely. The mean plasma fluorescence was $2.6 \mu \mathrm{g}$. per $100 \mathrm{ml}$., the range being 0 to $7.8 \mu \mathrm{g}$. per $100 \mathrm{ml}$. Seventeen of the 20 patients had levels below $5.0 \mu \mathrm{g}$. per $100 \mathrm{ml}$. The synthetic steroids may have contributed a little

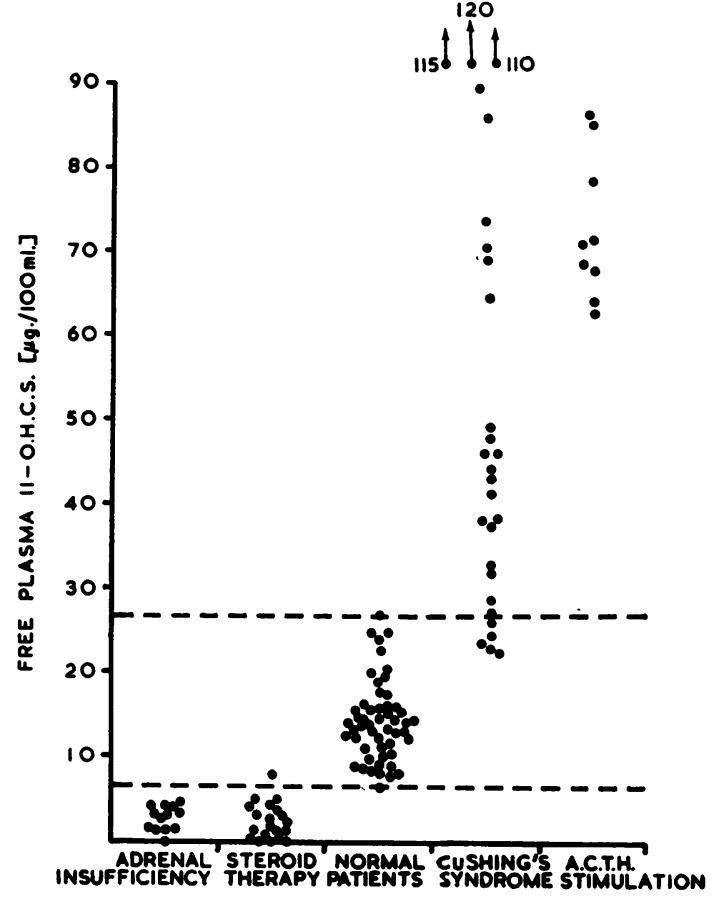

FIG. 1. The spectrum of adrenal cortical activity revealed by the measurement of free plasma 11-hydroxycorticoid concentrations. All the values plotted are 9 to 10 a.m. concentrations with the exception of those after A.C.T.H. (see text). The horizontal dotted lines indicate the normal range between 9 and 10 a.m.

fluorescence in this group, and one cannot be certain that endogenous corticosteroid secretion was completely abolished in either group.

ADRENAL HYPERFUNCTION Repeated estimations of the plasma 11-hydroxycorticoid concentrations between 9 and 10 a.m. were made in six patients with established Cushing's syndrome. Five patients always had levels above the upper limit of the normal range. One patient with bilateral adrenal hyperplasia had levels which usually fell inside the normal range, but the normal diurnal rhythm was absent and she maintained these levels throughout the 24 hours.

Nine hospital patients with normal 9 a.m. plasma levels were given 50 units of A.C.T.H. gel intramuscularly. The plasma 11-hydroxycorticoid levels five hours later ranged from 62.5 to $85.5 \mu \mathrm{g}$. per 100 $\mathrm{ml}$. (mean rise $54 \mu \mathrm{g}$.).

The spectrum of adrenal cortical activity revealed by the measurement of the plasma 11-hydroxycorticoid concentration by this method is illustrated in Fig. 1. 


\section{DISCUSSION}

The first quantitative method for estimating cortisol and corticosterone in plasma using sulphuric acidinduced fluorescence was developed by Sweat (1954). He used a silica gel micro-column to separate the individual steroids from the fat, cholesterol, and oestrogens in plasma. Several methods have been developed since for estimating corticosterone in rat plasma without attempting to separate the individual steroids (Silber et al., 1958; Guillemin et al., 1958; van der Vies et al., 1960). Instead, the crude plasma is first washed with petroleum ether to remove the lipids and later the plasma extracts are washed with $0 \cdot 1 \mathrm{~N} \mathrm{NaOH}$.

De Moor et al. (1960) have adapted this technique to measure the total free 11-hydroxycorticoids in human plasma. However, our attempts to reproduce their method were unsuccessful and it was found that the methylene chloride available in Great Britain contained large amounts of impurities which fluoresce strongly with concentrated sulphuric acid. These impurities can be removed, but even after this had been done consistent results were not obtained. One possible explanation for this was the presence of varying amounts of impurities in the batches of petroleum ether used to wash the plasma.

The method of De Moor et al. (1960) has therefore been modified, and at the same time simplified, by preliminary purification of the methylene chloride and by omission of the petroleum ether and alkali washes entirely since these have been found to be unnecessary. In addition, two alternative extraction procedures have been shown to give identical results and are simpler than their method of extraction. The fluorimetry has also been simplified by measuring the fluorescence of the extracts at a later time after mixing, thus enabling twice as many plasma extracts to be read simultaneously.

These modifications have not led to any loss of precision, accuracy, or specificity. It might be anticipated that the omission of the washes would increase the non-specific fluorescence due to interfering substances in the plasma, but this has not been found (Table IV).

Another attempt to adapt the technique of sulphuric acid-induced fluorescence to the measurement of free 11-hydroxycorticoids in human plasma has been made recently by Stewart et al. (1961). However, they used a $75 \%$ aqueous sulphuric acid reagent and corrected for the non-specific plasma fluorescence by taking readings at two, 45 , and 85 minutes after mixing. The presence of water in the sulphuric acid reagent delays the development of the fluorescence of the 11-hydroxycorticoids, and the plasma fluorescence two minutes after mixing is due entirely to non-specific substances. By comparing the relative rise of the fluorescence of corticosterone to cortisol with time they were able to calculate the amounts of corticosterone and cortisol separately in their plasma samples. Their method of extraction is more complicated than those described in this paper and they retained the petroleum ether and alkali washes. Their calculated value for the mean free plasma cortisol concentration at 9.30 a.m. in 27 normal young adults was $9.6 \pm 2.7 \mu \mathrm{g}$. per $100 \mathrm{ml}$.

By the present method the mean estimate of the free plasma 11-hydroxycorticoid concentration in 52 normal hospital patients between 9 and 10 a.m. was $14 \cdot 2 \mu \mathrm{g}$. per $100 \mathrm{ml}$. When this figure is corrected for the mean non-specific plasma fluorescence a corrected value of $11 \cdot 7 \mu \mathrm{g}$. per $100 \mathrm{ml}$. is obtained. Mean values for free cortisol in the plasma of normal subjects at this time of day have been determined by a number of workers using more elaborate methods and range from 7.8 to $13.3 \mu \mathrm{g}$. per $100 \mathrm{ml}$. (Bojesen, 1956; Lewis, 1957; Hale, Kratochvil, and Ellis, 1958; Gore and Baron, 1960; Braunsberg and James, 1960). The close agreement between the corrected mean value for total free 11-hydroxycorticoids and reported levels of free cortisol suggests that corticosterone can be present

TABLE IV

\begin{tabular}{|c|c|c|c|c|}
\hline \multirow[b]{2}{*}{ Author(s) } & \multicolumn{2}{|r|}{ NON-SPECIFIC FLUORESCENCE OF PLASMA } & \multirow[b]{2}{*}{$\begin{array}{l}\text { Mean } \\
(\mu g . / 100 \mathrm{ml} .)\end{array}$} & \multirow[b]{2}{*}{$\begin{array}{l}\text { Range } \\
(\mu \mathrm{g} . / 100 \mathrm{ml} .)\end{array}$} \\
\hline & Species & Treatment & & \\
\hline \multirow[t]{2}{*}{ Silber et al. (1958) } & Rat & Total adrenalectomy & - & 4.0 to 8.0 \\
\hline & & Hypophysectomy & & 6.0 to 7.0 \\
\hline $\begin{array}{l}\text { Guillemin et al. (1958) } \\
\text { Zenker and Bernstein }{ }^{1} \text { (1958) }\end{array}$ & $\begin{array}{l}\text { Rat } \\
\text { Rat }\end{array}$ & $\begin{array}{l}\text { Total adrenalectomy or hypophysectomy } \\
\text { Total adrenalectomy } \\
\text { Total adrenalectomy and oophorectomy }\end{array}$ & $\underline{-}$ & $\begin{array}{l}3.5 \text { to } 6 \cdot 5 \\
2 \cdot 1 \text { to } 3 \cdot 1 \\
1 \cdot 3 \text { to } 3 \cdot 2\end{array}$ \\
\hline $\begin{array}{l}\text { van der Vies et al. (1960) } \\
\text { De Moor et al. (1960) } \\
\text { This paper (1962) }\end{array}$ & $\begin{array}{l}\text { Rat } \\
\text { Man } \\
\text { Man }\end{array}$ & $\begin{array}{l}\text { Total adrenalectomy } \\
\text { Acute steroid suppression } \\
\text { Steroid suppression } \\
\text { Pituitary destruction with }{ }^{\circ 0} \mathrm{Yt}\end{array}$ & $\begin{array}{l}2 \cdot 2 \\
4 \cdot 3 \\
2 \cdot 6 \\
2 \cdot 5\end{array}$ & $\begin{array}{l}\overline{-} \\
\overline{0} \text { to } 7 \cdot 8 \\
0 \text { to } 4 \cdot 2\end{array}$ \\
\hline
\end{tabular}

'These authors omitted the petroleum ether wash.

'Petroleum ether and alkali washes omitted. 
only in very small amounts in plasma from normal subjects. De Moor et al. (1960) found a mean free plasma 11-hydroxycorticoid concentration of $21.9 \mu \mathrm{g}$. per $100 \mathrm{ml}$. in their normal hospital patients. Even when this figure is corrected for the mean nonspecific plasma fluorescence it is considerably higher than the mean value for free cortisol found by any of the groups mentioned above.

The present method is of great practical value in the clinical investigation of adrenal function. It is simple, accurate, and quick, and compares very favourably with the Porter-Silber method (Peterson, Karrer, and Guerra, 1957) used by us which takes at least three times as long and is much less sensitive. More elaborate methods using chromatography to separate the individual steroids before fluorimetry may be more specific, but are much less convenient for routine use. For example, only four estimations can be completed in a working week by the method described by Braunsberg and James (1960).

Using the present method it is possible to complete six plasma estimations in one and a half hours working single-handed. A diagnosis of acute adrenal insufficiency can be confirmed within one hour of taking blood from the patient. From 18 to 24 estimations can be completed in one working day. No interference from drugs administered to patients has been found with the exception of M.E.R. 29 (Triparanol). Since the synthetic steroids do not fluoresce significantly, it is of particular value in following endogenous corticosteroid secretion during adrenal suppression tests.

I am grateful to Dr. C. L. Cope for his advice and help in the preparation of this paper; Dr. B. H. B. Robinson for the results of his 17-hydroxycorticoid estimations; and Messrs. Upjohn Ltd., E. R. Squibb \& Sons, Imperial Chemical Industries, Ltd., and Glaxo Laboratories, Ltd., for pure steroid samples.

I am also indebted to the physicians of Hammersmith Hospital for permission to study the patients under their care and to their house physicians who collected the blood samples.

\section{REFERENCES}

Bayliss, R. I. S. (1955). Brit. med. J., 1, 495.

Bojesen, E. (1956). Scand. J. clin. Lab. Invest., 8, 55.

Bondy, P. K., Abelson, D., Scheuer, J., Tseu, T. K. L., and Upton, V. (1957). J. biol. Chem., 224, 47.

Braunsberg, H., and James, V. H. T. (1960). J. Endocrinol., 21, 327. Brown, J. B., Bulbrook, R. D., and Greenwood, F. C. (1957). Ibid., 16,41 .

Bush, I. E., and Sandberg, A. A. (1953). J. biol. Chem., 205, 783.

De Moor, P., Steeno, O., Raskin, M., and Hendrikx, A. (1960). Acta endocr. (Kbh.), 33, 297.

Fraser, R., and Joplin, G. F. (1960). Proc. roy. Soc. Med., 53, 81.

Gore, M. B. R., and Baron, D. N. (1960). J. Endocrinol., 21, 303.

Guillemin, R., Clayton, G. W., Smith, J. D., and Lipscomb, H. S. (1958). Endocrinology, 63, 349.

Hale, H. B., Kratochvil, C. H., and Ellis, J. P. (1958). J. clin. Endocrinol., 18, 1440.

Lewis, B. (1957). J. clin. Path., 10, 148.

Nelson, D. H., and Samuels, L. T. (1952). J. clin. Endocrinol., 12, 519.

Peterson, R. E., Wyngaarden, T. B., Guerra, S. L., Brodie, B. B., and Bunim, J. J. (1955). J. clin. Invest., 34, 1779.

- Karrer, A., and Guerra, S. L. (1957). Analyt. Chem., 29, 144.

Roy, E. J., and Brown, J. B. (1960). J. Endocrinol., $21,9$.

Silber, R. H., Busch, R. D., and Oslapas, R. (1958). Clin. Chem., 4, 278.

Snedecor, G. W. (1952). Biometrics, 8, 85.

Stewart, C. P., Albert-Recht, F., and Osman, L. M. (1961). Clin. chim. Acta, 6, 696.

Sweat, M. L. (1954). Analyt. Chem., 26, 773.

van der Vies, J., Bakker, R. F. M., and De Wied, D. (1960). Acta endocr. (Kbh.), 34, 513.

Wu, C., and Mason, H. L. (1958). Proc. Mayo Clin., 33, 627.

Zenker, N., and Bernstein, D. E. (1958). J. biol. Chem., 231, 695. 